\title{
Evaluasi Manajemen Pemeliharaan Ternak Sapi Bali (Bos sondaicus) pada Peternakan Rakyat di Kecamatan Kabawetan Kabupaten Kepahiang Provinsi Bengkulu
}

\section{Evaluation of Livestock Management Bali cattle (Bos sondaicus) on Ranch People in District Kabawetan Kepahiang District Bengkulu Province}

\author{
Riko Herdiansah $^{1}$, Dadang Suherman ${ }^{2}$, dan Sutriyono ${ }^{3}$ \\ ${ }^{1}$ Program Studi Peternakan Fakultas Peternakan Universitas Tulang Bawang Lampung \\ Jl. Gajah Mada. No. 34 Kota Baru, Bandar Lampung 35121 \\ ${ }^{2}$ Program Studi Peternakan Fakultas Pertanian Universitas Bengkulu \\ Jalan Raya W. R. Supratman, Kandang Limun, Bengkulu, 38371A \\ Corresponding e-mail: riko.herdiansah@utb.ac.id
}

\begin{abstract}
This study aims to evaluate the maintenance management of Bali cattle (Bos sondaicus) at the People's Farm in Kabawetan District, Kepahiang Regency, Bengkulu Province. The method used was a census with 97 breeders as respondents. The variables observed included respondent identity, seed selection management, reproduction management, harvest and post-harvest management. The results of the study were analyzed descriptively anallist. The results showed that the average respondents in the observation were of productive age and had the physical ability to support livestock raising. Farms in Kabawetan Subdistrict like Bali cows to be bred because Bali cows are considered to have more advantages than other cow breeds, breeders choose cows from their own breeds or from livestock breeding centers, this is done to find out the identity and find out the productivity of the seeds the. Balinese cattle breeders in the Kabawetan sub-district prefer a short marketing pattern by selling directly to local breeders, this pattern is chosen by breeders without involving many institutions in the livestock sales process and reducing costs incurred in the livestock marketing process. The conclusion of this study is that the management of Balinese cattle raising (bos sondaicus) on people's farms in Kabawetan District, Kepahiang Regency, Bengkulu Province is considered good in terms of its maintenance patterns.
\end{abstract}

Keywords: Maintenance Management, People's Farms, Bali Cattle

\begin{abstract}
ABSTRAK
Penelitian ini bertujuan untuk mengevaluasi manajemen pemeliharaan sapi bali (Bos sondaicus) pada Peternakan Rakyat di Kecamatan Kabawetan Kabupaten Kepahiang Provinsi Bengkulu. Metode yang digunakan adalah sensus dengan respoden 97 orang peternak sebagai responden. Variabel yang diamati meliputi identitas responden, manajemen pemilihan bibit, manajemen reproduksi, manajemen pemanenan dan pascapanen. Hasil penelitian dianalisis secara deskriptif anallist. Dari hasil penelitian menunjukkan rata-rata responden pada pengamatan berada pada umur produktif memiliki kemampuan fisik yang mendukung dalam pemeliharaan ternak. peternakan di Kecamatan Kabawetan menyukai bibit sapi bali untuk diternakkan karena sapi bali dinilai memiliki keunggulan lebih dibandingkan dengan bibit sapi lainnya, peternak memilih bibit sapi dari peranakan yang mereka miliki sendiri atau dari balai pembibitan ternak, hal tersebut dilakukan untuk mengetahui identitas dan mengetahui produktifitas dari bibit tersebut. para peternak sapi bali di kecamatan kabawetan lebih menyukai pola pemasaran yang singkat dengan langsung menjual kepada peternak lokal, pola ini dipilih oleh para peternak tanpa banyak melibatkan lembaga dalam proses penjualan ternak dan menekan biaya yang dikeluarkan dalam proses pemasaran ternak. Kesimpulan dari studi ini adalah manajemen pemeliharaan ternak sapi bali (bos sondaicus) pada peternakan rakyat di Kecamatan Kabawetan, Kabupaten Kepahiang Provinsi Bengkulu tergolong baik dilihat dari pola pemeliaraannya.
\end{abstract}

Kata kunci: Manajemen Pemeliharaan, Peternakan Rakyat, Sapi Bali 


\section{PENDAHULUAN}

Sapi bali merupakan salah satu bangsa sapi asli Indonesia yang sangat potensial sebagai penghasil daging. Sapi Bali berasal dari group Bibovine (Bos Sondaicus, Bos javanicus, Bibos banteng). Sapi Bali memiliki keunggulan dibandingkan dengan sapi lainnya antara lain mempunyai angka pertumbuhan yang cepat, adaptasi dengan lingkungan yang baik, dan penampilan reproduksi yang baik. Sapi Bali merupakan sapi yang paling banyak dipelihara pada peternakan kecil karena fertilitasnya baik dan angka kematian yang rendah (Purwantara et al., 2012).

Usaha peternakan rakyat di Indonesia sebagian besar ternak dipelihara oleh peternak berskala kecil dengan skala 2-4 ekor/peternak dengan lahan dan modal terbatas, teknik beternak secara tradisional, kandang menempel di luar rumah, pengelolaan limbah dan pengendalian penyakit belum baik serta pengawinan ternak masih secara alami (Isbandi, 2004).

Peternakan sapi potong mempunyai prospek yang baik dimasa depan, karena permintaan akan bahan-bahan yang berasal dari ternak akan terus meningkat seiring dengan jumlah penduduk, pendapatan dan kesadaran masyarakat untuk mengkonsumsi pangan bergizi tinggi sebagai pengaruh dari naiknya tingkat pendidikan rata-rata penduduk.

Evaluasi budidaya ternak merupakan suatu proses penilaian, dalam suatu usaha evaluasi dapat diartikan sebagai proses pengukuran akan evektifitas strategi yang di gunakan dalam upaya mencapai tujuan suatu usaha. Evaluasi budidaya di lakukan untuk mengetahui bagaimana perilaku masyarakat dalam pemeliharaan usaha sapi bali peternakan rakyat, faktor utama penunjang keberhasilan usaha peternakan sapi bali meliputi aspek manajemen pengelolaan usaha, manajemen pengelolaann usaha peternakan mencakup pada kegiatan manajemen pakan, perkawinan, perkandangan dan kesehatan ternak.

Kecamatan Kabawetan merupakan salah satu Kecamatan yang banyak membudidayakan sapi potong khususnya sapi bali yang masih berbasis peternakan rakyat. Permasalahan yang di hadapi Kecamatan Kabawetan sebagai sentra produksi sapi bali dikarenakan kurangnya pengetahuan peternak mengenai manajemen pemeliharaan yang baik. Untuk mengetahui lebih lanjut mengenai manajemen pemeliharaan usaha peternakan rakyat mulai dari asal bibit ternak, reproduksi, pencegahan penyakit, pakan dan pasca panen yang ada di Kecamatan Kabawetan Kabupaten Kepahiang, maka di lakukan penelitian yang berbentuk survei mengenai evaluasi manajemen pemeliharaan ternak sapi bali pada peternakan rakyat di Kecamatan Kabawetan Kabupaten Kepahiang Provinsi Bengkulu. 


\section{METODOLOGI}

Penelitian ini dilaksanakan di Kecamatan Kebawetan, Kabupatenn Kepahiang, Provinsi Bengkulu selama 2 (dua) bulan pemilihan lokasi dilakukan secara purposive. Responden pada penelitian ini seluruh peternak sapi bali yang ada di Kecamatan Kabawetan, Kabupaten Kepahiang, Provinsi Bengkulu dengan jumlah sampel ditetapkan secara sensus yaitu 97 orang peternak sebagai responden.

Data yang diperoleh dari penelitian ini terdiri dari data primer yang merupakan data dari hasil pengamatan langsung dilapangan meliputi identitas responden, manajemen pemilihan bibit, manajemen reproduksi, dan manajemen panen dan pascapanen serta data sekunder yaitu data yang berasal dari hasil intansi pemerintahan, lembaga, jurnal, e-book, buku yang berkaitan dengan penelitian pada literatur dan pustaka yang relevan.

Data yang didapatkan selanjutnya akan ditabulasi dan data akan disajikan dalam bentuk tabel dan dibahas secara deskriptif melalui perbandingan dengan hasil penelitian yang mendukung.

\section{HASIL DAN PEMBAHASAN}

\section{Identitas Responden}

Usaha peternakan sapi bali di Kecamatan Kabawetan pada umumnya dipelihara oleh peternak dengan skala yang masih relatif kecil sehingga tenaga kerja yang digunakan yaitu tenaga kerja keluarga. Pemeliharaan sapi bali yang diusahakan oleh peternak bersifat tabungan yang dapat dijual kapan pun pada saat membutuhkan dana lebih. Identitas responden yang diamati meliputi: Umur Responden, Jenis Kelamin, Pendidikan, Lama Beternak, Tujuan Pemeliharaan, dan Alasan Beternak. data mengenai identitas responden dapat dilihat pada Tabel. 1.

\begin{tabular}{|c|c|c|c|}
\hline No & Uraian & Jumlah & Persentase $(\%)$ \\
\hline \multirow[t]{6}{*}{1} & Umur Responden (Tahun) & & \\
\hline & $20-30$ & 14 & 14 \\
\hline & $31-40$ & 27 & 28 \\
\hline & $41-50$ & 36 & 37 \\
\hline & $>50$ & 20 & 21 \\
\hline & Jumlah & 97 & 100 \\
\hline \multirow[t]{4}{*}{2} & Jenis Kelamin & & \\
\hline & Laki-laki & 97 & 100 \\
\hline & Perempuan & 0 & 0 \\
\hline & Jumlah & 97 & 100 \\
\hline \multirow[t]{6}{*}{3} & Pendidikan Formal & & \\
\hline & SD & 34 & 35 \\
\hline & SMP & 41 & 42 \\
\hline & SMA/SMK & 22 & 23 \\
\hline & Sarjana & 0 & 0 \\
\hline & Jumlah & 97 & 100 \\
\hline
\end{tabular}




\begin{tabular}{clcc}
\hline No & Uraian & Jumlah & Persentase (\%) \\
\hline 4 & Lama Beternak Sapi (Tahun) & & \\
& $1-5$ & 37 & 38 \\
& $6-15$ & 51 & 53 \\
& $>15$ & 9 & 9 \\
\hline \multirow{2}{*}{5} & Jumlah & 97 & 100 \\
& Alasan Beternak Sapi Bali & & 8 \\
& Mudah Perawatan & 8 & 2 \\
& Pekerjaan Sampingan & 2 & 37 \\
& Pengahasilan Tambahan & 36 & 53 \\
\hline & Tabungan & 51 & 100 \\
\hline
\end{tabular}

Sumber : Data primer telah diolah, 2020

Berdasarkan hasil pengamatan Identitas responden yang dapat dilihat pada Tabel 1, usia peternak 20-30 tahun sebanyak (14\%), usia 31-40 tahun sebanyak (28\%), usia 41-54 tahun sebanyak (37\%), dan usia >50 tahun sebanyak (21\%), kondisi ini menunjukan bahwa rata-rata responden berada pada umur produktif yang memiliki kemampuan fisik yang mendukung dalam pemeliharaan ternak. Umur produktif merupakan tingkatan umur dimana seseorang mampu untuk menghasilkan produk maupun jasa. Zainal et al., (2012) menyatakan bahwa umur antara 20-59 tahun merupakan umur yang produktif, sedangkan umur dibawah 20 tahun merupakan umur yang belum produktif dan dapat dikategorikan sebagai usia sekolah, sedangkan umur 59 titik produktivitasnya telah melewati titik normal dan akan menurun sejalan dengan berkurangnya umur.

Tingkat pendidikan peternak sapi bali di Kecamatan Kabawetan Kabupaten Kepahiang sebagian besar tamat SMP sebanyak 41 peternak dengan presentase (42\%), SD sebanyak 34 peternak (35\%), SMA/SMK sebanyak 22 peternak (23\%). Keadaan ini menggambarkan bahwa separuh peternak pendidikan hanya tamat SD yang merupakan salah satu faktor penghambat dalam adanya teknologi. Pendidikan seseorang peternak merupakan salah satu faktor yang berpengaruh dalam usaha peternak, karena semakin tinggi tingkat pendidikan seseorang akan semakin mudah dalam menerima suatu teknologi yang dapat mendukung sehingga berpengaruh terhadap keberhasilan usahanya.

Pendidikan merupakan faktor penentu yang berperan penting sebagai perbedaan pemikiran peternak dalam memelihara sapi bali yang dimilikinya. Usaha peternakan faktor pendidikan diharapkan dapat membantu masyarakat dalam meningkatkan produksi dan produktifitas ternak yang dipelihara. Saediman, (2012), menyatakan bahwa tingkat pendidikan 
tentunya akan berdampak pada kemampuan manajemen usaha peternakan yang sedang dijalankan.

Lama pemeliharaan ternak sapi sangat 1-5 tahun sebanyak 37 dengan persentase 38, 615 tahun 51 orang dengan persentase 53 persen. Lebih dari 15 tahun sebanyak 9 orang dengan persentase 9. Pengalaman responden diukur dari seberapalama seorang responden tersebut terlibu dalam kegian usahanya. Semakin lama seorang responden dalam menekuni usahanya maka semakin banyak pengalaman yang telah diperoleh responden dalam menekuni usahanya, tingkat pengalaman ini akan sangat mempengarihi keberhasilan dan manajemen pemeliharaan sapi dalam beternak. Hal ini sesuai pendapat Handoko (2000), yang menyatakan bahwa pengalaman merupakan suatu faktor yang mempengaruhi kemampuan seseorang dalam menjalankan usahanya.

Alasan beternak sapi bali mudah dalam perawatan 8 orang, pekerjaan sampingan 2 orang penghasilan tambahan 36 (37\%), sebagai tabungan 51 orang (53\%). Kondisi ini menunjukan bahwa para peternak belum mengutamakan beternak sebagai profesi utama mereka, bagi para peternak dengan beternak sama halnya dengan mereka menabung, seketika mereka memerlukan uang secara mendadak mangka dengan mudah bisa menjual ternak mereka untuk memenuhi kebutuhan tersebut.

\section{Manajemen pemilihan bibit}

Salah satu faktor dalam manajmen beternak sapi Bali yang harus diperhatikan ialah dari segi memilihan bibit ternak yang akan dipelihara, biasanya pemilian bibit disesuaikan dengan tujuan pemeliharaan ,dengan mendapatkan bibit yang unggul maka produktivitas ternak tersebut semakin bagus selama pemeliharaan yang tertera pada Tabel 2.

Tabel 2. Manajemen pemilihan bibit ternak sapi bali di Kecamatan Kabawetan Kabupaten Kepahiang

\begin{tabular}{|c|c|c|c|}
\hline No & Uraian & Jumlah & Persentase $(\%)$ \\
\hline \multirow[t]{3}{*}{1} & Jenis Bibit Ternak & & \\
\hline & Sapi Bali & 97 & 100 \\
\hline & Jumlah & 97 & 100 \\
\hline \multirow[t]{5}{*}{2} & Bibit Ternak & & \\
\hline & Indukan & 37 & 38 \\
\hline & Dara & 25 & 26 \\
\hline & Anakan & 35 & 36 \\
\hline & Jumlah & 97 & 100 \\
\hline \multirow[t]{5}{*}{3} & Asal Bibit & & \\
\hline & Blantik & 22 & 23 \\
\hline & Peternak Lain & 24 & 25 \\
\hline & Peranakan & 51 & 53 \\
\hline & Jumlah & 97 & 100 \\
\hline
\end{tabular}




\begin{tabular}{rlcc}
\hline No & Uraian & Jumlah & Persentase (\%) \\
\hline 4 & Umur Bibit (Bulan) & & \\
& $1-5$ & 39 & 40 \\
& $6-10$ & 24 & 25 \\
& $11-15$ & 34 & 35 \\
\hline \multicolumn{2}{c}{ Jumlah } & 97 & 100 \\
\hline & Bobot Sapi (Kg) & & \\
& $10-50$ & 8 & 8 \\
& $51-100$ & 24 & 55 \\
& $101-150$ & 53 & 12 \\
\hline & $151-200$ & 12 & 100 \\
\hline
\end{tabular}

Sumber : Data primer telah diolah, 2020

Berdasarkan hasil pengamatan pemilihan bibi ternak yang dapat dilihat pada Tabel.2, jenis bibit ternak yang dipelihara ialah sapi bali 97 ekor sebanyak (100\%), kondisi ini menunjukan para peternak menyukai bibit sapi bali untuk diternakkan karena sapi bali yang dinilai memiliki keunggulan lebih dibandingkan dengan bibit sapi lainnya, salah satunya manajemen pemeliharaannya yang mudah dan mudah beradaptasi dengan lingkungan baru, hal ini sesuai dengan Abidin (2002) menyatakan keunggulan sapi bali adalah mudah beradaptasi dengan lingkungan baru, sehingga sering disebut ternak perintis. Selain itu Sapi Bali juga mudah dikendalikan, jinak, dapat hidup hanya dengan memanfaatkan hijauan yang kurang bergizi, tidak selektif terhadap makanan dan memiliki daya cerna terhadap makanan serat yang cukup baik (Batan, 2006).

Bibit ternak yang dimiliki peternak di Kecamatan Kabawetan Kabupaten Kepahiang indukan 37 ekor sebanyak (38\%), dara 25 ekor sebanyak (26\%), dan anakan 35 sebanyak $(36 \%)$, keadaan ini menggambarkan bibit tenak paling banyak terdapat pada indukan yang dapat dipelihara untuk mendapatkan bibit di priode selanjutnya. Asal bibit yang dipelihara oleh para peternak sebagian besar berasal dari peranakan 51 ekor sebanyak (53\%), peternakan lain 24 ekor sebanyak (24\%), dan berasal dai belantik 22 ekor sebanyak (23\%), kondisi ini menggambarkan para peternak memilih bibit sapi dari peranakan yang mereka miliki sendiri atau dari balai pembibitan ternak, hal tersebut dilakukan untuk mengetahui identitas dan mengetahui produktifitas dari bibit tersebut.

Umur bibit yang dipelihara oleh para peternak di Kecamatan Kabawetan Kabupaten Kepahiang 1-5 bulan sebanyak (40\%), 6-10 bulan sebanyak (25\%), an 11-15 bulan sebanyak (35\%), kondisi ini menunjukkan para peternak memilih sapi yang akan dipelihara menyukai bibit sapi yang berumur 1-5 bulan, sedangkan untuk bobot sapi yang akan dipelihara oleh peternak sebagian besar memilik berat 101-150 Kg sebanyak (55\%), 51-100 Kg sebanyak (25\%), 151-200 Kg sebanyak (12\%), dan 10-50 Kg sebanyak (8\%). Kondisi ini menunjukkan 
bahwa para peternak secara tidak langsung telah melakukan penyeleksian dari bibit ternak yang akan mereka pelihara, salah satunya dengan cara melat pertumbuhan bibit yang akan dipelihara dengan perkiraan umur yang mereka pilih, hal ini dilakukan untuk mencari bibit unggul dan perbaikan genetik untuk ternak tersebut.

\section{Manajemen reproduksi}

Sapi Bali, walaupun ukurannya kecil tetapi disukai di Indonesia, salah satu penyebabnya adalah kemampuan adaptasi reproduksinya yang luar biasa dibawah cekaman lingkungan yang keras.yang tertera pada Tabel 3.

Tabel 3. Manajemen reproduksi ternak sapi bali di Kecamatan Kabawetan Kabupaten Kepahiang

\begin{tabular}{clcc}
\hline No & \multicolumn{1}{c}{ Uraian } & Jumlah & Persentase (\%) \\
\hline 1 & Jenis Perkawinan & & \\
& IB & 81 & 84 \\
& Alami & 16 & 160 \\
\hline & Jumlah & 97 & \\
\hline 2 & Umur Ternak Dikawinkan (Bulan) & & 84 \\
& $10-15$ & 81 & 16 \\
& $16-20$ & 16 & 100 \\
& Jumlah & 97 & 100 \\
\hline 3 & Lama Kebuntingan (Hari) & & 100 \\
& 278 & 97 & 100 \\
\hline & Jumlah & 97 & 100 \\
\hline 4 & Lama Menyusui (Hari) & & \\
& 90 & 97 & 29 \\
\hline & Jumlah & 97 & 71 \\
\hline 5 & Umur Sapi Siap Sapih (Bulan) & & 100 \\
& $3-4$ & 28 & \\
& $5-6$ & 69 & 97 \\
\hline
\end{tabular}

Sumber : Data primer telah diolah, 2020

Berdasaran hasil pengamatan manajemen reprodoksi pada sapi bali yang dipelihara di Kecamatan Kabawetan Kabupaten Kepahiang yang apat dilihat pada Tabel 3. Jenis perkawinan yang paling banyak dilakukan peternak ialah IB sebanyak $84 \%$ dan perkawinan secara alami sebanyak 16\%, kondisi ini menunjukan bahwa bahwa para peternak lebih menyukai jenis perkawinan IB dibandingkan dengan kawin alami, hal ini dikarenakan dibandingkan dengan kawin alami perkawinan dengan IB dinilai memiliki banyak keunggulan yang lebih menguntungkan bagi para peternak. Hal ini jga dijadikan sebagai alasan solusi untuk memperbaiki permasalahan pengembangan sapi bali, melalui perkawinan dengan teknologi inseminasibuatan (IB) dan pengaturan penggunaan pejantan unggul di padang pengembalaan. Hal ini berperan penting dalam menghindari perkawinan dalam (inbreeding) 
dan perkawinan menggunakan pejantan tidak layak. Pendapat serupa juga dikemukakan Sulin (2008) bahwa perkawinan ternak sapi dengan teknologi IB dapat mencegah inbreeding.

Dalam memanajemen pemeliharaannya para peternak dominan mengawinkan ternaknya pada umur 10-15 bulan sebanyak $84 \%$ dan pada umur 16-20 bulan sebanyak 16\%, Lama kebuntingan pada ternak sapi pada masa pemeliharaannya Kecamatan Kabawetan Kabupaten Kepahiang ialah selama 278 hari sebanyak 100\%, sedankan lama menyusui 90 hari sebanyak 100\%. Menurut Saladin (1993), lama bunting pada ternak sapi berkisar antara 270290 hari, Devendra et al. (1973), lama kebuntingan pada ternak sapi bali adalah kisaran 276295 hari, Menurut Iskandar (2011) bahwa penyebab lama kebuntingan ternak dipengaruhi oleh bangsa sapi, jenis kelamin dan jumlah anak yang dikandung, umur induk, musim, dan letak geografis.

Sedangkan untuk umur sapi siap sapih pada sapi bali yang dipelihara di Kecamatan Kabawetan Kabupaten Kepahiang untuk 3-4 bulan sebanyak 29\% dan untuk yang berumur 56 bulan sebanyak 71\%. hal ini kurang sesuai dengan pendapat Santoso (1995) yang menyatakan bahwa pedet ideal disapih umur 6-7 bulan, sedangkan di tempat penelitian para peternak lebih awal melakukan penyapihan pada ternak yang dilakukan 3-6 bulan, hl ini dikarenakan para peternak ingin lebih awal dalam mengawinkan ternak untuk di periode selanjutnya.

\section{Manajemen Pemanenan dan Pascapanen}

Penanganan manajemen pemanenan dan pascapanen ternak sapi bali di Kecamatan Kabawetan Kabupaten Kepahiang tertera pada Tabel 4.

Tabel 4. Manajemen pemanenan dan pascapanen ternak sapi bali di Kecamatan Kabawetan Kabupaten Kepahiang

\begin{tabular}{|c|c|c|c|}
\hline No & Uraian & Jumlah & Persentase (\%) \\
\hline \multirow[t]{5}{*}{1} & Umur Panen (Bulan) & & \\
\hline & $5-10$ & 18 & 19 \\
\hline & $11-20$ & 48 & 49 \\
\hline & $>21$ & 31 & 32 \\
\hline & Jumlah & 97 & 100 \\
\hline \multirow[t]{5}{*}{2} & Kriteria Penjualan & & \\
\hline & Anakan & 39 & 40 \\
\hline & Indukan & 7 & 7 \\
\hline & Pejantan & 51 & 53 \\
\hline & Jumlah & 97 & 100 \\
\hline \multirow[t]{5}{*}{3} & Pola Pemasaran & & \\
\hline & Tengkulak & 38 & 39 \\
\hline & Peternak Lain & 46 & 47 \\
\hline & Konsumen & 13 & 13 \\
\hline & Jumlah & 97 & 100 \\
\hline
\end{tabular}




\begin{tabular}{clcc}
\hline No & Uraian & Jumlah & Persentase (\%) \\
\hline 4 & Harga Jual Ternak & 40 & \\
& Anakan Rp.3.000.000,- s.d Rp. 5.000.000,- & 7 & 41 \\
& Indukan Rp.9.000.000,- s.d Rp. 10.000.000,- & 50 & 7 \\
& Jantan Rp.12.000.000,-s.d Rp. 15.000.000,- & 97 & 100 \\
\hline
\end{tabular}

Sumber : Data primer telah diolah, 2020

Berdasaran hasil pengamatan data panen ternak sapi bali yang dipelihara di Kecamatan Kabawetan Kabupaten Kepahiang yang apat dilihat pada Tabel 4. Jika dilihat dari umur panen ternak sebagian besar ternak dipanen pada umur 20 bulan sebanyak (49\%), pada umuer panen $>21$ sebanyak (32\%) dan pada umur panen 5-10 bulan sebanyak (19\%).

Jika dilihat dari kriteria penjualan para peternak sebagian besar menjual ternak pejantan sebanyak 51 dengan persentase 53\%, penjualan anakan sebanyak 39 dengan persentase $40 \%$ dan dengan penjualan indukan sebanyak 7 dengan persentase $7 \%$. Kondisi ini menunjukan bahwa para peternak lebih memilih ternak jantan mereka untuk dijual, salah satu alasannya ilalah lebih memilih mempertahankan indukan untuk dijadikan indukan bibit di priode selanjutnya demi keberlangsungan peternakan tersebut, dan harga penjualan jantan leih besar dibandingkan dengan penjualan indukan dan anakan.

Untuk pola pemasaran yang dilakukan peternak untuk menjual ternak mereka sebagian besar ternak dijual kepada peternak lain sebanyak $47 \%$, dijual kepada tengkulak sebanyak $39 \%$, dan dijualkan langsung kepada konsumen sebanyak 13\%. Jika dilihat dari pola pemasarannya para peternak lebih menyukai pola pmasaran yang singkat dengan langsung menjuat kepada peternak, pola ini dipilih oleh para peternak tanpa banyak melibatkan lembaga dalam proses penjualan ternak dan menekan biaya yang dikeluarkan dalam proses pemasaran ternak. Hal tersebut sesuai dengan yang dikemukakan oleh Syahidulhaq (2012) semakin sedikit lembaga yang terlibat dalam saluran pemasaran maka efesiensi akan semakin rendah dan nilai shere harga akan semakin tinggi

Untuk harga jual ternak para peternak menentukan penjualan anakan dengan haga Rp.3.000.000,- s.d Rp.5.000.000,- sebanyak 41\%, untuk penjualan indukan dengan harga Rp.9.000.000,- s.d Rp.10.000.000,- sebanyak 7\% dan untuk penjualan janta dengan harga Rp.12.000.000,- s.d Rp.15.000.000,- sebanyak 52\%. Kisaran harga yang mereka tentukan didasari pada permodalan selama masa pemeliharaan ternak, dalam menentukan harga jual ternak para peternak telah memperhitungkan dari modal awal pemeliharaan selain itu harga jual menjadi factor penting dalam menentukan keberhasilan penjual tersebut. Hal ini sependapat dengan Reksohadiprodjo(1992) yang menyatakan bahwa harga barang sekarang menjadi faktor penting yang menentukan keberhasilan penjualan. Apalagi pada masa inflasi harga merupakan unsur yang paling mendapatkan sorotan konsumen. Perusahaan yang 
menjual barang akan dijual juga oleh perusahaan lain tetapi dengan harga yang lebih murah pasti akan mendapatkan langganan lebih banyak sehingga orang harus berhati-hati dalam menentukan harga.

\section{KESIMPULAN}

Hasil penelitian dan pembahasan dapat disimpulkan bahwa Manajemen Pemeliharaan Ternak Sapi Bali (Bos sondaicus) pada Peternakan Rakyat di Kecamatan Kabawetan, Kabupaten Kepahiang Provinsi Bengkulu tergolong baik dilihat dari pola pemeliaraannya.

\section{DAFTAR PUSTAKA}

Abidin, Z. 2002. Penggemukan Sapi Potong. Agromedia pustaka. Jakarta.

Batan, I.W. 2006. Sapi Bali dan Penyakitnya. Fakultas Kedokteran Hewan Universitas Udayana. Denpasar Bali.

Devendra, C.T., K.C. Lee, Pathmasingam. 1973. The Productivity of bali cattle in Malaysia. J. Agric 49:183-197.

Handoko, T. Hani. 2000. Manajemen Personalia dan Sumberdaya Manusia. Edisi Kedua (Agustus), Yogyakarta: BPFE.

Iskandar. 2011. Performan reproduksi sapi po pada dataran rendah dan dataran tinggi di Provinsi Jambi. Jurnal Ilmiah Ilmu-Ilmu Peternakan, 14 (1) : 51-61.

Reksorahardjo, S dan Handoko, T.H. 1992. Kebijaksanaan perusahaan. Konsep Dasar dan Studi Kasus. Edisi Kedua. BPFE. Yogyakarta.

Saladin, R. 1993. Teknik Produksi Sapi Potong. Fakultas Peternakan Universitas Andalas, Sumatera Barat.

Syahidulhaq, Y. 2012. Analisis pemasaran itik di Kabupaten Sukoharjo. Skripsi. Fakultas Pertanian. Universitas Sebelas Maret. Surakarta.

Sulin, I. 2008. Identifikasi performa produksi dan service periodsapi Pesisir dan hasil persilangan inseminasi buatan di kabupatenPesisir Selatan. Jurnal Embrio (1): 29-34. 